\title{
Helios: a tangible and augmented environment to learn optical phenomena in astronomy
}

\author{
Stéphanie Fleck, Martin Hachet
}

Stéphanie Fleck, Martin Hachet, "Helios: a tangible and augmented environment to learn optical phenomena in astronomy," Proc. SPIE 9793, Education and Training in Optics and Photonics: ETOP 2015, 979331 (8 October 2015); doi: 10.1117/12.2223249

SPIE Event: Education and Training in Optics and Photonics: ETOP 2015, 2015, Bordeaux, France 


\title{
Helios: a tangible and augmented environment to learn optical
} phenomena in astronomy

\author{
Stéphanie Fleck ${ }^{\mathrm{a} *}$, Martin Hachet ${ }^{\mathrm{b}}$ \\ ${ }^{a}$ Université de Lorraine - ESPE \& PErSEUs (EA 7312) Île du Saulcy, CS 60228, F - 57045 Metz \\ cedex 01, France \\ ${ }^{\mathrm{b}}$ Inria Bordeaux - Potioc, 200 av. De la vieille tour, F - 33405 Talence, France
}

\begin{abstract}
France is among the few countries that have integrated astronomy in primary school levels. However, for fifteen years, a lot of studies have shown that children have difficulties in understanding elementary astronomic phenomena such as day/night alternation, seasons or moon phases' evolution. To understand these phenomena, learners have to mentally construct 3D perceptions of aster motions and to understand how light propagates from an allocentric point of view. Therefore, $4-5$ grades children ( 8 to 11 years old), who are developing their spatial cognition, have many difficulties to assimilate geometric optical problems that are linked to astronomy.

To make astronomical learning more efficient for young pupils, we have designed an Augmented Inquiry-Based Learning Environment (AIBLE): HELIOS. Because manipulations in astronomy are intrinsically not possible, we propose to manipulate the underlying model. With HELIOS, virtual replicas of the Sun, Moon and Earth are directly manipulated from tangible manipulations. This digital support combines the possibilities of Augmented Reality (AR) while maintaining intuitive interactions following the principles of didactic of sciences. Light properties are taken into account and shadows of Earth and Moon are directly produced by an omnidirectional light source associated to the virtual Sun. This AR environment provides users with experiences they would otherwise not be able to experiment in the physical world. Our main goal is that students can take active control of their learning, express and support their ideas, make predictions and hypotheses, and test them by conducting investigations.
\end{abstract}

Keywords : Augmented reality, tangible interactions, astronomy, ray optic, primary school

\section{INTRODUCTION}

Astronomy has been taught at elementary school in France since 1985. The program of the grades 4-5 (French grade $=$ cycle 3 for children from 8 to 11 years old), spread over 3 years, is focused on the solar system, asters motion and specifically of Sun, Earth and Moon. At these grades, most of the astronomical learning goals mobilize the understanding of the shadows origins observed on Earth (Night and Day alternation origins, Influences on season, and so on) and on Moon (e.g. Moon Phases and eclipses origins), in direct relationship with the positions of the asters in space.

However, in their efforts to make sense of the surrounding world, children learn informally explanations for many optical phenomena in daily life long (e.g. shadows origin, reflexion, night and day...) before official instruction are provided at schools. As a result, an abundance of knowledge is spontaneously formed before any formal learning takes place [10]. From a cognitive point of view, children construct their knowledge of the world and the universe on the basis of two information sources: observations of the world and explanations given by other people [29]. A lot of studies have shown that children and many adults of various cultures have difficulties in understanding contemporary scientific explanations of elementary astronomic phenomena $[1,8,11,16,27,30]$. If the initial knowledge are integrated and consistently used, people tend to reinterpret the new information to form new synthetic models instead of scientific ones $[11,12,31]$. This can be a source of problems, especially when children's preliminary knowledge radically differs from what is taught in school. Therefore, teachers have to propose pedagogical supports specifically oriented to overcome the barriers to learning. Teaching astronomical concepts can be an incredibly difficult task due to the need to switch points of reference to fully understand what is happening. Additionally, within constructivist views of learning, astronomy is difficult for students to explore. Currently, very few-targeted teaching material is available for teachers and learners in France. The available resources are mainly textbooks and physical models. Consequently, there is a real need to develop

*stephanie.fleck@univ-lorraine.fr

Education and Training in Optics and Photonics: ETOP 2015, edited by Eric Cormier, Laurent Sarger Proc. of SPIE Vol. 9793, 979331 - (c) 2015 SPIE, IEEE, OSA, ICO · doi: 10.1117/12.2223249 
digital astronomical didactic materials. In order to overcome some barriers to learning, we have designed a Hybrid Environment dedicated to the learning of the Influence of Sun in the Solar System. This system, called HELIOS, is a tangible user interface for an Augmented Reality (AR) environment adapted to Inquiry-Based Sciences Education (IBSE). HELIOS, can thus be described as an Augmented and Inquiry-Based Learning Environment (AIBLE).

\section{THE NEED TO OVERCOME BARRIERS TO LEARNING}

In the astronomy program of the primary school, one of the most difficult skills for children is to construct the causal relationship between the light source position and the relative position of the different asters in constant evolution. 4-5 grades children ( 8 to 11 years old), who are in full development of their spatial cognition, have many difficulties to assimilate geometric optical problems that are linked to astronomy $[18,19,26]$.

Light is immaterial and imperceptible. Movement of non-material natural entities such as energy, heat or light are complex for children because they are detached from children's perceptual experiences [2, 9, 10, 15, 17, 21]. For example, children frequently understand light as a concept centered on the light source. Therefore, they have many difficulties to locate light in space and most of them ignore the space in which light beams propagate [20]. Consequently, children do not spontaneously plan the form of different shadows because they do not understand the notion of rectilinear propagation of light. Therefore, teacher have to explain that the shadow which they see can be obtained by drawing lines leaving the light source and passing by the limit of the object. This requires 3D geometry skills and abstraction capacities.

However, at this stage of development, most of children still need concrete, topological information to construct mental images $[18,19]$. For children from grades $4-5$, all the evidences that structure the environmental perception for an adult are not totally developed. Children have to use topological spatial relationships (properties of single object or configuration) before being able to use projective or Euclidean representations.

Moreover, the geocentric position of child observations and the large scale of phenomena constitute barriers to understand astral motions and related influence of the Sun position on shadows that project onto Earth and Moon. To understand these phenomena, learners have to mentally construct a 3D perception of aster motions and to understand how light propagates from an allocentric point of view. However, 8-11 years children cannot access to large-scale space to observe and solve these types of astronomical problems.

Therefore, to enable children to understand astronomical phenomena, two kinds of conception fields are involved: 1- the objects motions and 2- the changes in objects, both related by cause and effect relationships with the primary light source position. Children have to mobilize optic and geometry knowledge and skills such as:

- Identify the source of light in the solar systems and understand that light sources are from two sorts:

$\circ \quad$ Sun is a primary light source; Moon and Earth are secondary light sources. They reflect the sun light.

- Light travels in a straight path and can be reflected:

- Sun light travels could be associated to straight lines; so it is possible to use geometry to find the light path

- Earth and Moon are obstacles for the light resulting in three types of shadows (own shadow, projected shadow and conical shadow).

- Half of the Earth and lunar surfaces facing the Sun are always sunlit.

- Geometrical shape (spherical) of each aster produces specific shadows shapes.

- Distinguish rotation and revolution:

○ Rotation refers to the movement or path of the earth or a heavenly body turning on itself, on an imaginary line called a rotation axis, and with a specific rotation period.

- Revolution refers to the action of a body that moves around another ("orbiting"), Earth perform a revolution around the Sun (planet) and the Moon perform a similar revolution around the Earth (natural satellite).

- Revolution and rotation of asters inducing modification of the terrestrial perception of lightening zone

In this context, as in all activities involving physical knowledge, children actions on objects and their observations of the objects reaction are both important [13]. Therefore, manipulation of physical objects could provide valuable feedback to 
construct the causal relationship between the light source position and the shadows production on Earth and Moon. Moreover, learners should investigate and manipulate in order to become conscious of complex phenomena, change their misconceptions and construct scientific knowledge [5, 28]. Ideally, students will mobilize the skills required for scientific and technological inquiry for solving those problems [14, 23, 32].

Unfortunately, manipulations in astronomy are naturally impossible therefore require using models. Classical physical models (Fig. 1) constrain to work in a dark environment. With such models, the symbolism of the representation is low, and the important complexity of handling the physical elements affects the scientific learning for children [7, 22, 25]. Despite all of that, those types of models are still used because little alternatives exist.

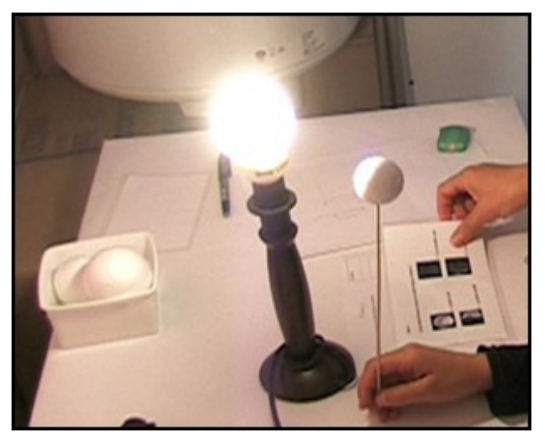

Figure 1. Example of a physical model used in primary classroom to teach the origin of the Day/Night on Earth. It is simply composed of plastic balls and a light bulb.

\section{AIBLE-HELIOS®, AN AUGMENTED REALITY AND TANGIBLE INTERFACE}

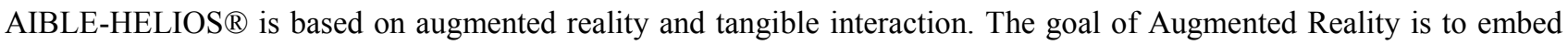
virtual objects into the real world. To do so, several technologies exist. One is to use see-through Head-MountedDisplays (HMD). Another is to project directly digital content onto physical objects (spatial augmented-reality). These two approaches can provide rich user experiences. However, they are too complex to be implemented concretely in a classroom. Consequently, we chose a simpler implementation of AR where a camera films the real environment. The recorded video stream is augmented with virtual objects, and the resulting images are displayed on a screen in real-time (See Figure 3).

In HELIOS, users manipulate the virtual asters by physically moving markers, following a tangible approach. Tangible interaction is "an emerging post-WIMP (Windows, Icons, Menus and Pointer) approach that is concerned with providing tangible representations to digital information and controls" [24]. One of the strengths of tangible interface is their "situatedness": interaction takes place in a real- world environment that often hides most of the technological aspects to

Tangible User Interfaces (TUIs) involve gesturing, physical movement and embodiment [4] that play an important role in our learning goals. Gestures associated to TUIs can provide external representations of a problem or an object, which play a role in problem solving and learning. It corresponds to the possible enactments of concepts by students [3].

\section{Iterative design principles}

As exposed in a previous study [6] we have first follow instructional design principles. Instructional design consists in elaborating learning activities and learning technologies that take into account the targeted learning outcomes, the specificity of the contents to be learned, the peculiarities of the learners, and the principles of educational psychology, i.e. how people learn [3]. In a second time, we based the development of a new prototype on Human-Computer Interaction (HCI) ergonomics principles. Human-computer interaction is a discipline concerned with the design, evaluation and implementation of interactive computing systems for human use and with the study of major phenomena 
surrounding them. Therefore, the current prototype was design, in an iterative process, after two user studies, conducted in real classroom situation and not in lab. User tests involving children from grades 4-5 were focused on :

- efficacy i.e.. the capacity or power of a system to produce a desired effect,

- efficiency i.e. the resources expended by the user in relation to the accuracy and achiness of the goals,

- usability i.e. the extent to which a product can be used by specified users to achieve specified goals with satisfaction in a specified context of use

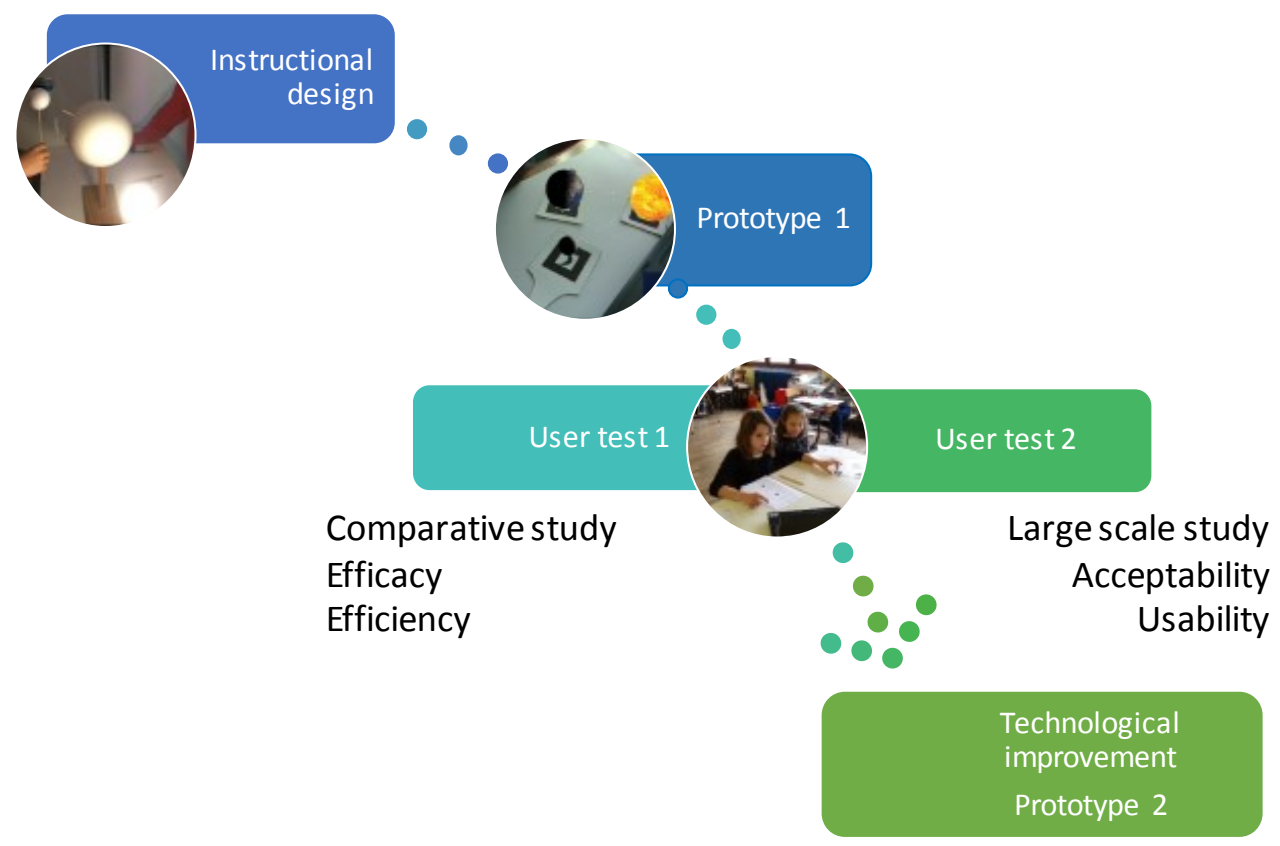

Figure 2: design principles

\section{Technical description of the current prototype.}

The current prototype of AIBLE-HELIOS ${ }^{\circledR}$ runs under Unity3D Pro 5 and the tracking of the markers is achieved thanks to OpenCV. Among the features we have developed that enhance the previous versions, we integrated an illumination of the scene based on particles. We also added visual feedback such as shadow cones (Fig. 3), virtual lines symbolising the light paths or the optional display of meridians.

This augmented learning environment enhances significantly astronomical learning. Because the AR model provides visual guides and realistic representations, pupils benefit from a reduced complexity to construct a scientific comprehension of phenomena. HELIOS facilitates children's perception of astronomical objects, of the light path and so they perceive the causal effect between light and shadows in an astronomical scale. User studies confirms that coexistence of virtual and real objects lowers abstraction levels of young learners by providing concrete spatial and scientific references. Easy perception of concretes indicators provided by the physical environment associated to virtual asters facilitates spatial information encoding and assesses learning of spatial layout of this environment. HELIOS provides children with visual tools essential for success in spatial tasks and so upgrades awareness of scientific explanation. Moreover, visual interactions promoted by AR develop spatial strategies skills, which could be re-invested in problem solving tasks. Children using HELIOS are able to plan their own mental processes and to engage intuitive manipulations. These tangible interactions contribute to spatial abilities development, which are required to construct scientific conceptions of astronomical phenomena. HELIOS, as expected for an inquiry-based environment, really allows heuristic investigations, which fosters consciousness of the origin of astronomical phenomena. 


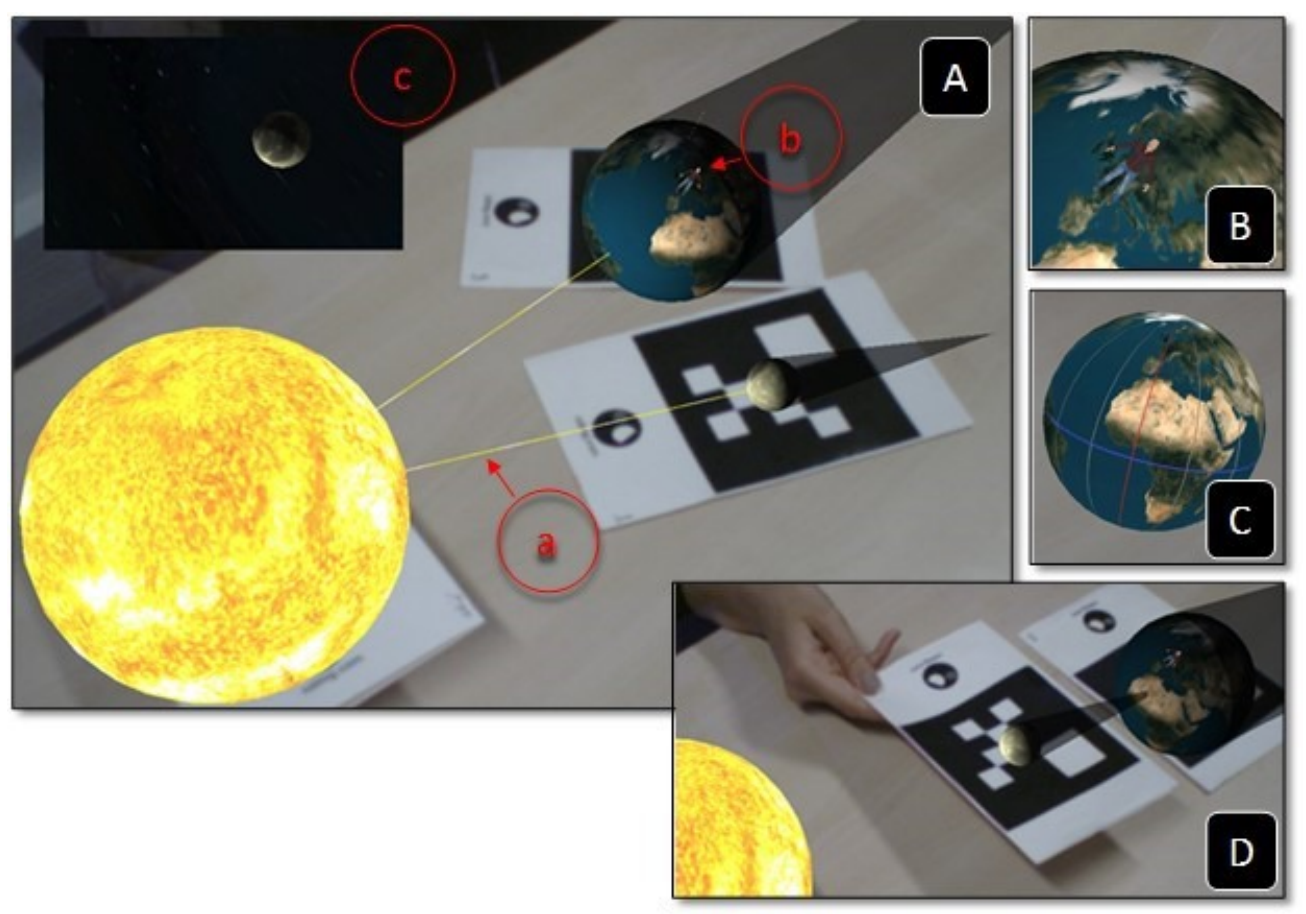

Figure 3: A) Example of first person perspective of the AR environment. B) Detail of the terrestrial observer associated to the viewport. C) optional display of meridians. D) Example of manipulation producing a solar eclipse on the African continent.

Visual guides support learners: (a) dashed-lines between bodies' centers (b) a terrestrial observer (c) Viewport showing the terrestrial observer's view in real-time.

\section{FUTURE WORKS}

In the future, we will continue enhancing the functionalities of AIBLE-HELIOS ${ }^{\circ}$. We will also conduct experiments that take into account full professional constraints. This includes the fact that all children will work at the same time and the possibilities for teachers to conduct their own learning activities using this tool.

\section{ACKNOWLEDGMENTS}

AIBLE-HELIOS ${ }^{\circledR}$ development is financially supported by the SATT Grand-Est. Thank you to Jérémy Laviole and Fatma ben Guefrech for their contributions at this step of development. We want to thank the Ministry of National Education school inspectors for allowing us to conduct studies in classrooms. The authors thank the schools, their teachers and all the pupils who took part in this study. And finally, we want to sincerely thank Gilles Simon for his collaboration at the early stage of the development of AIBLE-HELIOS ${ }^{\circledR}$.

\section{REFERENCES}

1. Bryce, T. G. K., and Blown, E. J., "The Novice-Expert Continuum in Astronomy Knowledge," International journal of science education, 23(4), 545-587 (2012).

2. Colin, P., Chauvet, F. o., and Viennot, L., "Reading images in optics: Students' difficulties and teachers' views," International Journal of Science Education, 24(3), 313-332 (2002).

3. Cuendet, S., Bonnard, Q., Do-Lenh, S., and Dillenbourg, P., "Designing augmented reality for the classroom," Computers \& Education, 68(0), 557-569 (2013).

4. Cuendet, S., Jermann, P., and Dillenbourg, P., "Tangible interfaces: when physical-virtual coupling may be detrimental to learning." 49-58. 
5. Duit, R., and Treagust, D. F., "Conceptual change: a powerful framework for improving science teaching and learning," International journal of science education, 25(6), 671-688 (2003).

6. Fleck, S., Hachet, M., and Bastien, J. M. C., [Marker-based augmented reality: Instructional-design to improve children interactions with astronomical concepts], Boston, MA USA(2015).

7. Fleck, S., and Simon, G., [An Augmented Reality Environment for Astronomy Learning in Elementary Grades: An Exploratory Study], Bordeaux(2013).

8. Frede, V., "Pre-service elementary teacher's conceptions about astronomy," Advances in Space Research, 38, 22372246 (2006).

9. Galili, I., "Students' conceptual change in geometrical optics," International Journal of Science Education, 18(7), 847-868 (1996).

10. Galili, I., and Hazan, A., "Learners' knowledge in optics: interpretation, structure and analysis," International Journal of Science Education, 22(1), 57-88 (2000).

11. Hannust, T., and Kikas, E., "Children's knowledge of astronomy and its change in the course of learning," Early Childhood Research Quarterly, 22, 89-104 (2007).

12. Hannust, T., and Kikas, E., "Young children's acquisition of knowledge about the Earth: A longitudinal study," Journal of Experimental Child Psychology, 107, 164-180 (2010).

13. Kamii, C., and DeVries, R., [Physical knowledge in preschool education: Implications of Piaget's theory] Teachers College Press, (1993).

14. Minner, D. D., Levy, A. J., and Century, J., "Inquiry-based science instruction-what is it and does it matter? Results from a research synthesis years 1984 to 2002," Journal of Research in Science Teaching, 47(4), 474-496 (2010).

15. Mumba, F., Mbewe, S., and Chabalengula, V. M., "Elementary School Teachers' Familiarity, Conceptual Knowledge, and Interest in Light," International Journal of Science Education, 1-25 (2014).

16. Nobes, G., Martin, A. E., and Panagiotaki, G., "The development of scientific knowledge of the Earth," British Journal of Developmental Psychology, 23(1), 47-64 (2005).

17. Palacios, F. J. P., Cazorla, F. N., and Madrid, A. C., "Misconceptions on geometric optics and their association with relevant educational variables," International Journal of Science Education, 11(3), 273-286 (1989).

18. Piaget, J., and Inhelder, B., [The child's conception of space] Routledge and Kegan Paul, London(1956).

19. Piaget, J., Inhelder, B., and Szeminska, A., [The child's conception of geometry], (1960).

20. Ravanis, K., Christidou, V., and Hatzinikita, V., "Enhancing Conceptual Change in Preschool Children's Representations of Light: A Sociocognitive Approach," Research in Science Education, 43(6), 2257-2276 (2013).

21. Ravanis, K., and Papamichaël, Y., "Procédures didactiques de déstabilisation du système de représentations spontanées des élèves pour la propagation de la lumière," Didaskalia, 7, 43-61 (1995).

22. Rolando, J.-M., "Astronomie à l'école élémentaire: quelques réfléxions sur la construction des compétences..." Grand N, 74, 99-107 (2004).

23. Saltiel, E., Worth, K., and Duque, M., [POLLEN - L'enseignement des sciences fondé sur l'investigation. Conseils pour les enseignants] La main à la pâte, Montrouge(2009).

24. Shaer, O., "Tangible User Interfaces: Past, Present, and Future Directions " Foundations and Trends in HumanComputer Interaction, 1-2(3), 1-137 (2009).

25. Shelton, B. E., and Hedley, N. R., [Using augmented reality for teaching Earth-Sun relationships to undergraduate geography students], (2002).

26. Spencer, C., Blades, M., and Morsley, K., [The child in the physical environment: The development of spatial knowledge and cognition] Wiley Chichester, (1989).

27. Straatemeier, M., van der Maas, H. L. J., and Jansen, B. R. J., "Children's knowledge of the earth: new methodoligical and statistical appraoch.," Journal of Experimental Child Psychology, 100, 276-296 (2008).

28. Vosniadou, S., "Capturing and modeling the process of conceptual change," Learning and Instruction, 4(1), 45-69 (1994).

29. Vosniadou, S., and Brewer, W. F., "Mental models of the earth: A study of conceptual change in childhood," Cognitive psychology, 24(4), 535-585 (1992).

30. Vosniadou, S., and Brewer, W. F., "Mental Models of the Day/Night Cycle," Cognitive Science, 18(1), 123-183 (1994).

31. Vosniadou, S., Skopeliti, I., and Ikospentaki, K., "Reconsidering the role of artifacts in reasoning: Children's understanding of the globe as a model of the Earth," Learning and Instruction(15), 333-351 (2005).

32. Worth, K., [Science in early childhood classrooms: Content and process] Cedar Falls, IA(2010). 